\title{
CONSERVATION MANAGEMENT PLAN CHESTE WORKERS UNIVERSITY AUDITORIUM (SPAIN). A GETTY FOUNDATION KEEPING IT MODERN GRANT
}

\author{
C. Jordá ${ }^{1}$, M. Palomares ${ }^{1,}$ *, F. Iborra ${ }^{1}$, C. Gradolí ${ }^{1}$, P. Herrero ${ }^{1}$, F. Usó ${ }^{1}$ \\ ${ }^{1}$ Universitat Politècnica de València, Valencia, Spain - (cjorda, mapafi, feibber, cargrama, pashervi, ferusmar)@cpa.upv.es
}

\section{Commission II - WG II/8}

\begin{abstract}
KEY WORDS: Universidad Laboral de Cheste, Fernando Moreno Barberá, KIM Grant Award, Conservation Management Plan,
\end{abstract} Modern Architecture.

\begin{abstract}
:
Universidades laborales, or workers' universities, were set up throughout Spain during the years of the dictatorship and were aimed at professionally training the working classes. The architect Fernando Moreno Barbera was the author of four centers: those of Las Palmas, 1970-73, Toledo, 1970-78, Malaga 1972-78 and Cheste 1967-69, his work reflecting an undoubted assimilation of the Modern legacy. Cheste Workers University was a guidance center designed to house as many as 5,000 boarding students of up to 14 years of age. The auditorium, currently closed for safety reasons, is an important architectural symbol and, as such, has been included in the Ministry of Culture's National Plan for the Conservation of the 20th Century Heritage. A Conservation Management Plan is currently being drafted on the initiative of the Getty Foundation. This paper explains some details of this initiative and provides a preview of the strategy employed.
\end{abstract}

\section{THE UNIVERSIDAD LABORAL DE CHESTE}

Universidades laborales, or workers' universities, were set up throughout Spain during the years of the dictatorship and were aimed at professionally training the working classes. Their charitable-educational nature was established by law in 1955 , although several date back to before that official date. The Universidad Laboral de Gijón (1946-1957) was the first to be built, as reflected in the traditional and academic architecture of Luis Moya.

\subsection{Fernando Moreno Barberá}

Fernando Moreno Barberá (1913-98), one of the most important architects involved, was the author of four centers: those of Las Palmas, 1970-73, Toledo, 1970-78, Malaga 1972-78 and Cheste 1967-69, his work reflecting an undoubted assimilation of the Modern legacy. The Universidad Laboral de Cheste, the largest of these, marks a huge increase in scale as it was designed to house as many as 5,000 boarding students of up to 14 years of age.

Its architect, who graduated in Madrid in 1940, is well-known through the publications of DOCOMOMO Ibérico. His career is outstanding for his mastery of the trade and for his notable planning skills. Both characteristics may have been strengthened during his stay between 1941 and 1943 at the office of professor Paul Bonatz (1877-1956), an outstanding architect from Stuttgart, who was at the time building bridges for the motorways of the Third Reich. Later, his possible relationship with Richard Neutra, during the installation of North American bases in Spain, could also have been significant.

Before starting work on Cheste, Fernando Moreno Barberá had shown notable skill in designing university buildings in Valencia, which present similarities with those of this workers' university. The Modern Movement once again appears as the point of reference, being masterfully interpreted and evident in a vigorous plasticity that trusts in the expressive possibilities of concrete and several elaborate solar protection systems. The Cheste complex fits comfortably within several other similar international experiences, such as those of Brazil, Mexico and Caracas, all of which a cosmopolitan professional would have been familiar with through his travels or publications.

\subsection{Universidad Laboral de Cheste}

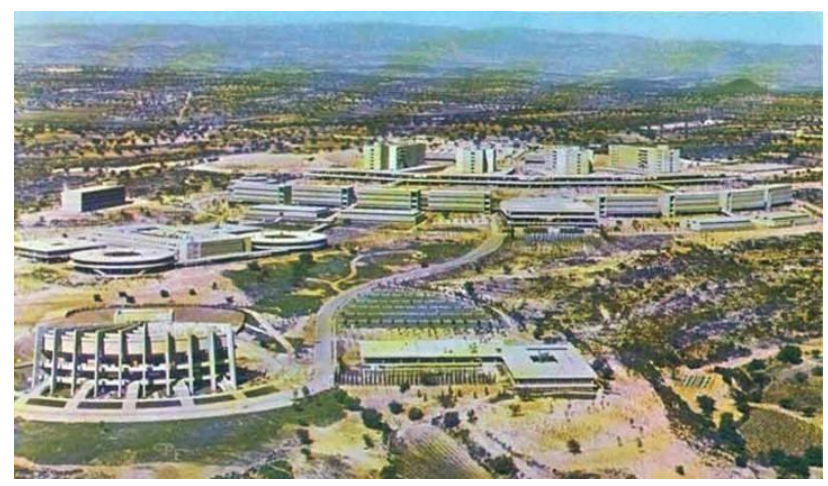

Figure 1. The Universidad Laboral de Cheste. Arch CTAV.

This ambitious project, envisaged for a different site on the coast, had to be urgently adapted to a hillier site at $22 \mathrm{kms}$ from Valencia. The better conditions of the latter site recommended the change of location. Thus, a rural landscape was transformed into a small gardened city aimed at training young people, as part of the policy of General Franco, whose propaganda boasted of "record construction in Spain, built in a minimum period of time" (Jordá, 2010).

The complex program of requirements was approached by grouping together the various functions onto levels, under the

\footnotetext{
* Corresponding author
} 
dual premise of taking advantage of the topology and of avoiding the drawbacks of overcrowding that simultaneous usage would produce. The sports facilities were installed on the highest level with the four-building residential area built on a common platform lower down. Beneath these were two swimming pools and, still further down, the teaching areas with eight classrooms and four workshops, as well as the departmental building which, as it occupied the greatest space in the center, provides a hierarchical structure to this area. The nucleus of dining rooms, of great importance for so many students, consists of two circular and two square buildings situated around the grand services building. The complex also has, to one side, a medical center and oratory with columned peristyle, similar to a tempietto. Finally, the representation zone is given special emphasis through the singular volume of the Main Hall that looks out onto an open-air auditorium.

Outstanding in the work of Moreno Barberá is both his talent for coming up with technical solutions and for building, which, in Cheste, is evident in the impeccable execution achieved, with reinforced concrete playing the lead role, although sharing responsibilities with brick and wood. This provides a good example of his very characteristic treatment of textures, all of which was governed by a strict economy and a module of 1.60 meters throughout the entire work.

\subsubsection{Sports area, residences, public space and teaching sector}

Next to the sports fields, at the top, two large gymnasiums were built consisting of two delicately positioned box-like structures in the Miesian manner, whose main entrances have sliding doors that open almost completely. The structure is bare, with large ribs providing a technical solution for the roofing, at the same time as acting as identifying elements, along with its brise soleil and a horizontal louver awning.

When it came to finding a solution to the accommodation of a large number of boarders with simultaneous activities, the criterion of avoiding overcrowding is clearly evident in the residences. His approach was to divide the accommodation up into four six-storey buildings of the same height, each with its own staircase, so resulting in a singular elevation composition, alternating parapets with empty spaces.

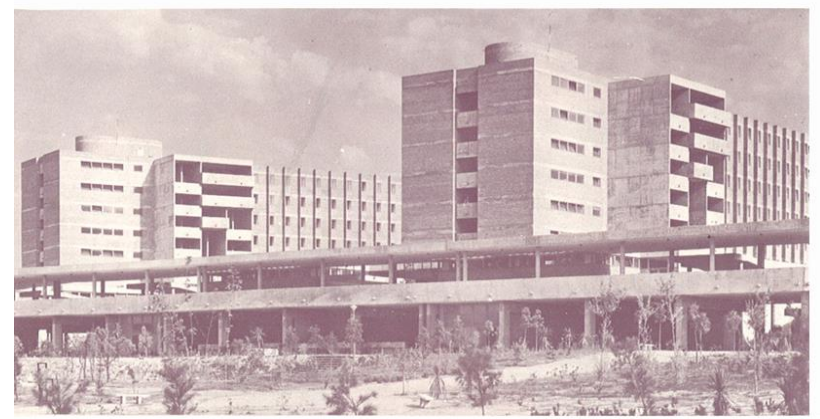

Figure 2. Residences area. Architecture 142, 1970.

As in the Athens Charter, traffic is segregated, the study of pedestrian circulation constituting a particular point of interest. These architectonic elements take on a leading role, the concrete strips marking and gradually colonizing the territory by creating spaces for coexistence and shelter for daily transit.

The change of location meant greater space for the teaching sector, as, in Cheste, there was space for eight classrooms in a row, as well as four independent workshops situated in front, whose magnificent section presents lateral and overhead illumination. As with most of his installations, there is the reiterated use of horizontal parasols, this being the resource most commonly used by Moreno Barberá and, obviously, reminding us of Le Corbusier.

This area was developed upon two circular segments, with good views and parallel to the perimeter of the grand residential platform, its center being occupied by a luminous departmental building with an enormous gardened courtyard that was covered with creeper plants thanks to several spectacular prefabricated beams. Next to the sculptural spiral staircase, of Brazilian inspiration, the free-standing ground floors provide another example of Modernism, as well as a sheltered area for the students to enjoy with an interesting visual permeability that, regrettably, has been lost in the lecture room buildings.

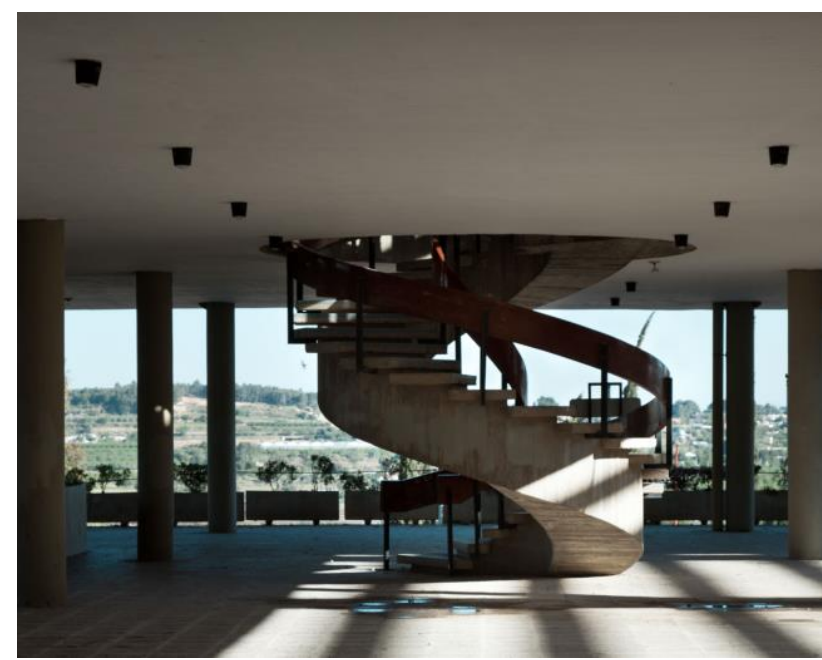

Figure 3. Departmental building. Spiral staircase. Photography Ximo Michavila.

1.2.2 Services area, dining rooms, representation area and auditorium

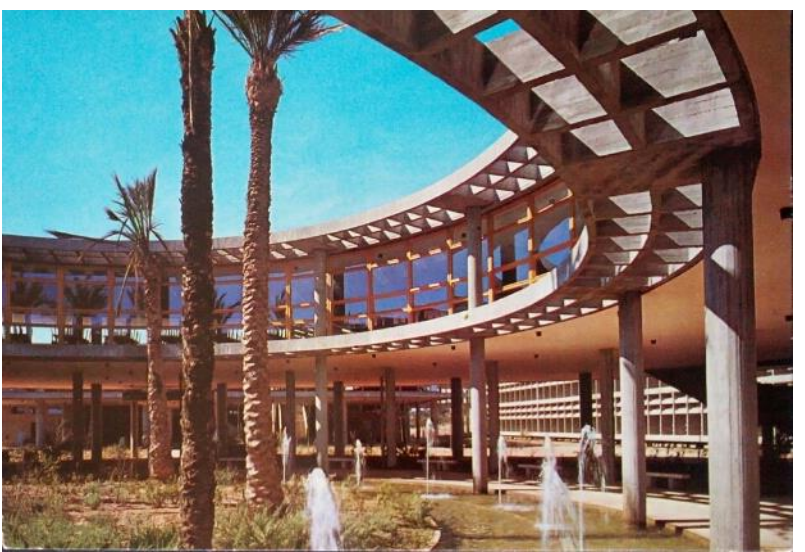

Figure 4. Circular dining room. External louvers. Architecture 142,1970

The services building, with kitchens, laundry and staff dormitories put the organizational capacity of the architect to the test. He had to consult abundant international bibliography, dedicating many pages of his technical report to the minute study of the various jobs and huge storage space that had to be provided for. The fact that most of the activities were going to be simultaneous for large groups and that the decision had been 
taken to reject the depressing model of immense common dining rooms meant that the building program had to be divided into four constructions, which in turn, were sub-divided by partitions into six ambients, in harmony with the layout of the four residences. All the dining rooms have a large open central gardened area.

Close by is a public square bordered by cypresses that opens out to the representation space. Within the two grand intersecting rectangles are located the cafeteria, administration and President's office in a large single-storey pavilion, which, with continuous paving, provides an open and fluid space. The most interesting piece is the Salón de Grados, the ceiling of which reflects the attractive play of light and shade of the external louvers similar to the meshes of the Brasilia Campus.

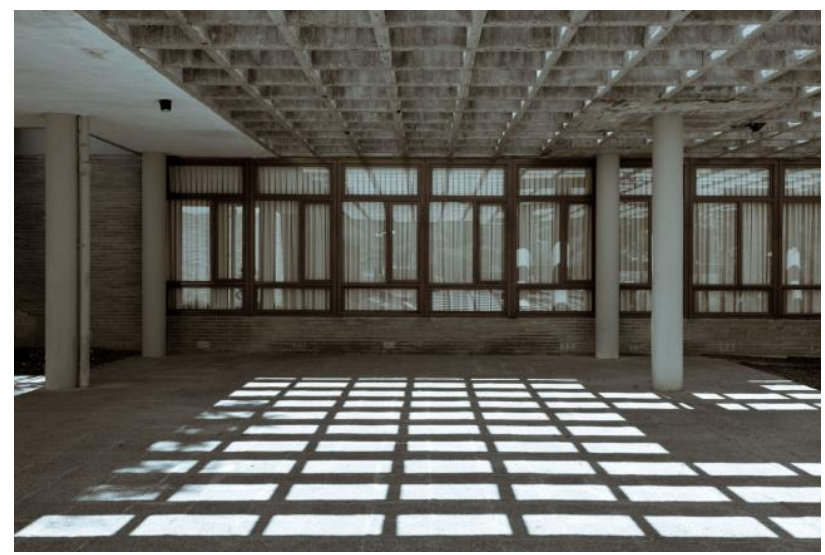

Figure 5. President's office. External louvers. Photography Ximo Michavila.

The Aula Magna of Cheste, or auditorium, with its 5,234 seats, was among the largest halls of its time, even though it was built under strict economic criteria. It is complemented by an outside amphitheater, providing a sculptural sounding board. However, the singular image of the so-called Main Hall is characterized by its supporting structure,

\section{THE CONSERVATION AND MANAGEMENT PLAN (CMP)}

With the arrival of democracy, the educational dismantling of the worker universities resulted in them becoming functionally obsolete, giving way to the partial abandonment of their installations.

The architectural interest in the Universidad Laboral de Cheste is undoubted and it is a good time to focus attention on it as it is gradually deteriorating. A Master Plan is advisable as a tool for diagnosing and coordinating intervention strategies, as without that tool, which is commonly employed in heritage projects, isolated actions have been undertaken that have greatly undermined the essence and character of the work. (Jordá, Palomares, 2013)

With this aim, a team of architects from the History of Architecture Department at the Polytechnic University of Valencia, headed by Professor Carmen Jordá, we drew up a conservation proposal and management plan for the auditorium at the Cheste Worker University to apply for the "Keeping it Modern Grant" (KIM) of the Getty Foundation.

Entitled "Conservation Management Plan: Cheste Workers University auditorium" the proposal concerns one building, the auditorium, the most relevant building of the Universidad Laboral de Cheste complex.

\subsection{Auditorium}

The auditorium, currently closed for safety reasons, is an important architectural symbol and, as such, has been included in the Ministry of Culture's National Plan for the Conservation of the 20th Century.

The idea of the project, in terms of economy and despite its large size, is to maintain the austerity and the same criterion of minimum cost that was common to all the constructions of the Cheste teaching center. Concrete is the main protagonist of the auditorium, making up the supporting structure with large beams as the forceful lateral enclosures, where the sunlight slants in emphasizing the cutting of the formwork. The technical solution of reinforced concrete porticos with post-tensioned ribs, defining a singular image, can be said to create a huge sculpture of colossal dimensions and impeccable execution that welcomes the visitor.

For its special academic purpose, the auditorium of Cheste basically had to be designed to meet the acoustic conditions of the human voice, complete visibility from the first row to the last corner and a spatial organization for the type of diverse activities that were going to take place inside it. Likewise, and given the type of habitual user - a boisterous public- it was necessary to facilitate to the maximum the filling and emptying of the auditorium in the shortest possible time, and so circulations and accesses had to be painstakingly studied.

Finally we should consider, in addition to costs, the climatic conditions, circumstances that led to adopting the solution of closing only the great hall proper, so that all the stairs, accesses, corridors and galleries were built in the open air. Following this decision, it is interesting to speculate on the expressive possibilities that the architect was seeking with the image of the complex and its consequent visual impact. Whatever he thought, he achieved his purpose in an outstanding manner. So much so that it is difficult to understand how such a successful scheme could be altered later with the perimeter closure wall that was added in the 1990s. (Jordá, 2005)
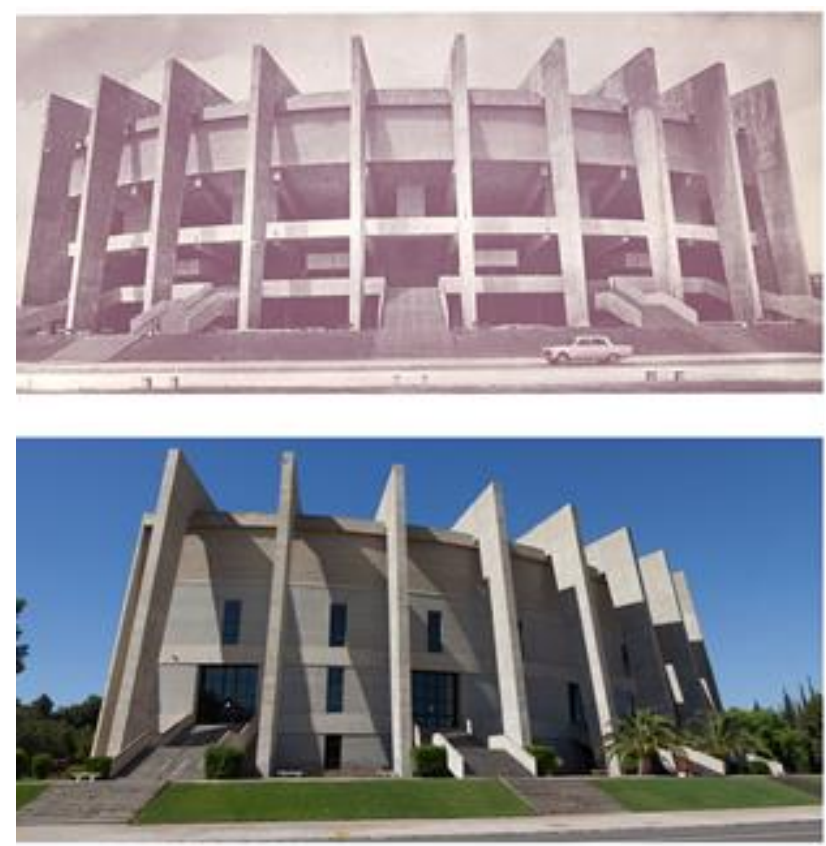
Figure 6. The auditorium. Present state with recent interventions.

Accesses and circulations, very well resolved, are organized through five cores of reinforced concrete stairs to a gallery, exterior in origin, from which one enters directly to the back of the stalls. Both the entrance and the exit are made in a straight line from the stairs. In turn, from this gallery one climbs up another staircase to another upper gallery of the same width and from which the vomitoria lead to the amphitheater. These upper galleries and the structure of the amphitheater are supported on large cantilevers that rest on pillars, defining another completely autonomous structure with respect to the porticoes of the roof.

The general layout of the auditorium features two separate parts, the room itself (or interior part) and the amphitheater, which extends laterally with seats that reach the stage, avoiding establishing categories in the spectators. Inside it is covered by a false acoustic ceiling, whose studied design provided the necessary reflection of sound to all locations, reinforcing it mainly in the back rows of the amphitheater.

The stage, with a width of 16 meters, like that of a small theater, is reminiscent of the Aula Magna of Caracas, mentioned expressly in the Cheste architectural memory. This dimension makes it necessary to adopt a fan shape for the correct position of the seats, which is externalized through the radial arrangement of the huge roof beams. Nevertheless, it must be said that the image of Cheste is more indebted, in broad strokes, to the project of 1931 for the Palace of the Soviets of Le Corbusier and Pierre Jeanneret than that of the Venezuelan solution, although the latter was also a huge inspiration.

The volume of the Cheste auditorium is completed with two symmetrical blocks of two floors for dressing rooms and storage, which were built with brick walls and brise soleil on the façades, as were many of the buildings of the Worker University of Cheste.

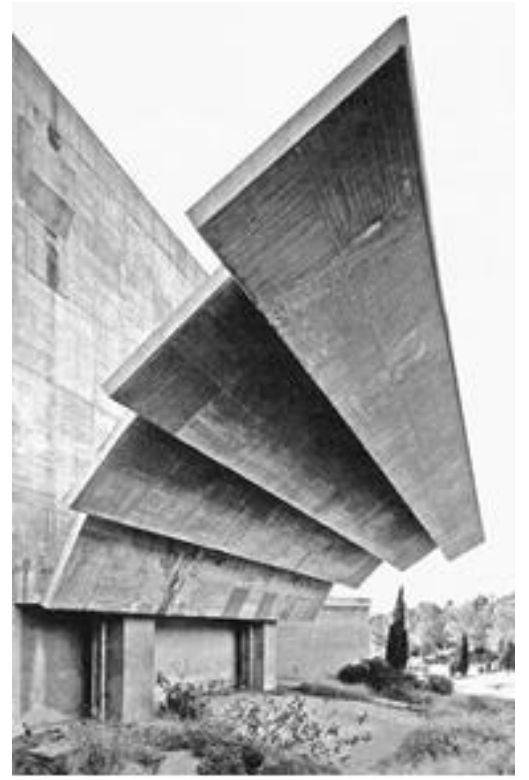

Figure 7. Auditorium. Sounding board. Architecture 142, 1970.

Behind the large building, an outdoor auditorium was built, designed for gymnastic performances, band concerts or similar activities. The natural slope of the hillside facilitated the services for the stage through the mentioned rear door.
The most impressive element in this area is the sounding board or sound amplifying system. It consists of a large reflective screen on the rear exit of the stage, designed to deflect the sound towards the spectators of the exterior auditorium. The stepped piece, made of reinforced concrete and supported by large cantilevered beams, constitutes an element of maximum interest that attracts the eye and characterizes the rear façade of the auditorium of the Cheste Worker University.

\subsection{The Conservation Management Plan}

The Conservation Management Plan has the backing of the Consellería of Education, Culture and Sport and the Polytechnic University of Valencia, together with significant and explicit support from organizations such as International DoCoMoMo, Iberian DoCoMoMo, Europa Nostra, Eduardo Torroja Foundation del CSIC, Real Academia de Bellas Artes de San Carlos and Palau de Les Arts.

2.2.1 Current state: The enormous volume dominates the landscape but exhibited in its day the perforations of its strategic system of accesses and circulations -a visual delight- which today has been greatly undetermined due to a perimeter enclosure wall whose elimination is recommendable. Fortunately, this action, which has undermined the main façade of the auditorium, is reversible. It would also be desirable for the frontal image to recover its original state, with its creative system of perforations, circulations and accesses to the open air.

Apparently, there is no major damage to the colossal posttensioned concrete structure, except for a large fissure in one of the central ribs, which can be seen above all in the encounter with the slab of the roof. Although a more detailed study is required, it is most likely that this fissure is a consequence of the expansion of the building's roof, which lacks expansion joints despite its enormous dimensions. It would be necessary to repair this fissure and solve the dilatation problem in some way.

More complicated is the issue of cracking in the external sounding board, an element of great visual impact and bold design, which presents worryingly significant fissures for an external feature. This piece should be studied carefully, calculated and if necessary reinforced in the most discreet way possible, so as not to alter its sculptural image too much.

One of the main challenges of the building is to undertake structural repairs without altering its image (Palomares, 2012). It is too frequent to find cases (starting with other buildings of the Worker University itself) in which the removal of the coatings and the repair by means of epoxy mortars is carried out in a totally disrespectful way, leaving patches of different tones and textures. The importance of using the formwork finish as a compositional resource requires developing in this case alternative methods that are as non-invasive as possible and that, in the essential cases of action, guarantee the conservation of the texture and original image in the repaired area. This criterion will be applicable to the auditorium, to the rest of the buildings of the Worker University and, in general, to all the architecture of brutalist inspiration in which the layout of the boards of the formwork acquire an intentional aesthetic value.

Inside, the auditorium the furniture has clearly aged, requiring either re-upholstery or replacement. The electrical installations are also clearly obsolete. Part of the acoustic coating of the walls is in poor condition due to water leaks, caused by lack of 
maintenance. Likewise, the significant deterioration in the woodwork of the dressing room area, where the bathrooms and the rest of the original installations are practically intact, is a consequence of the abandonment and lack of maintenance. This is not the case of the stage box and the stage, which have been replaced and modernized at some point in the life of the building.

In general, it can be said that the main problem presented by the Cheste auditorium is the lack of use and maintenance, so it is necessary to give it a function and adapt it in the best possible way, providing accessibility for people with reduced mobility and perhaps improving the acoustic conditions, but avoiding betraying the essence of the original project.

It is therefore essential that before proposing a large-scale intervention, a serious study of possibilities be carried out, with the participation of citizens and local and regional institutions, so that the success of the rehabilitation operation is guaranteed and the building can be allocated to cultural initiatives of interest.

It is also necessary to establish a comprehensive maintenance plan that includes basic operations such as periodic cleaning of vegetation that may arise on the roof, control of downpipes to prevent plugging and annual varnishing of woodwork, mainly the most exposed and oriented to north.

2.2.2 Goals: In order to achieve its public reopening and recover the original image, now distorted, the Conservation Management Plan will compile and catalogue different studies focusing on obtaining the corresponding regional and municipal protection of the auditorium, verifying the structure, checking the acoustic conditions, auditing the efficiency and sustainability of the facilities and analyzing the state of the concrete. This last aspect is relevant since, during the construction of the Universidad Laboral de Cheste, the consequences of the aging process of the material and the development of possible future pathologies were unknown.

The Plan will help to identify and protect the original elements of the construction, as well as to meet the legal requirements necessary for the new implementation of this emblematic structure, with updated uses based on proposals collected in participation processes that will involve various citizen and institutional agents.

\section{KEEPING IT MODERN GRANT}

The Keeping it Modern (KIM) program is an international grant initiative of the Getty Foundation that was launched as a continuation of its deep commitment to architectural conservation, focusing on the important buildings of the 20th century. This program complements the Getty Conservation Institute's Conservation of Modern Architecture (CMAI) initiative.

In modern architecture, architects and engineers use experimental materials and innovative construction techniques to create innovative forms and advance new philosophical approaches to architecture. The cutting-edge building materials and structural systems that define the modern movement have often been untested and have not always worked well over time. Therefore, one objective of the program is to develop the necessary protocols for conservation treatment, supporting heritage professionals who do not always have sufficient scientific data on the nature and behavior of experimental materials and construction techniques.
Another of the program's objectives is to support the development of projects that can serve as models for the conservation of other 20th century buildings, due to their excellence in forward planning and the quality of execution. A good example of this is the Salk Institute Conservation Project which addresses the aging and long-term care of the building's teak window wall assemblies, one of the main elements of the architectural complex.

The KIM program started in 2014 and over the last six years it has awarded 64 research projects on modern architecture works all over the world. If we analyze the results, we can see that two issues stand out: the interest of the works and the solvency of the applicant institutions. It would, therefore, seem to be a good idea to start an analysis of KIM strategy by studying these two issues.

\subsection{Project analysis}

A convenient first step to take in analyzing these works is to establish a typological classification of those 64 projects.

Thus, in this brief analysis, it can be seen that most have been focused on the single-family dwelling with such significant works as Charles \& Ray Eames House (1949), Le Corbusier apartment (1934) in Porte Molitor, Robie House (1909) and Max Liebling House (1936), all of these in the first call for projects or Hill House (1904), Gropius House (1938), Rietveld Schröder House (1924) or Strutt House (1956), which were presented and selected in the 2015 call. In the following years, it should be pointed out, the study of individual houses decreases, although not the quality, Eileen Gray's E-1027 (1929) having been selected in two calls. In the 2018 call, however, no single-family dwelling appears. The same cannot be said for collective residence program, where the sample is considerably smaller and is limited only to the calls for 2015 and 2017. The three works that make up the group present very different types, from residential blocks like Het Schip (1920) (M. de Klerk) to skyscrapers such as Price Tower (1956) (F. Ll. Wright). The third type is made up of "Collegi" buildings (1962) (G. De Carlo) "an organism in the form of a city" resolved from simple and repeated structural elements that respond to the topography.

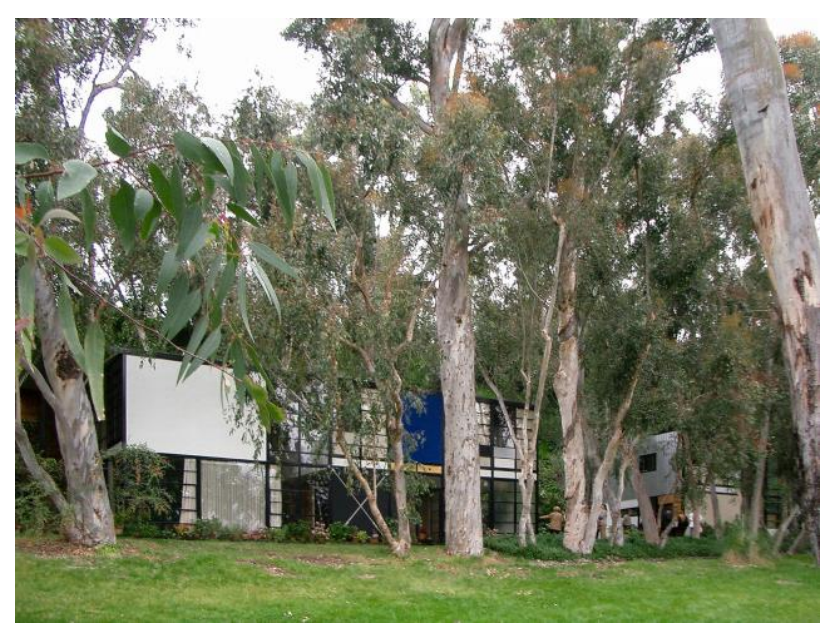

Figure 8. Charles \& Ray Eames House. Photography Ximo Michavila.

Among facility buildings are several devoted to health, represented, in this case, by one of the most iconic buildings of 
the Modern Movement, Paimio Sanatorium (1933), by A. Aalto, which was specifically designed for the cure of tuberculosis and now needs to find a new suitable use.

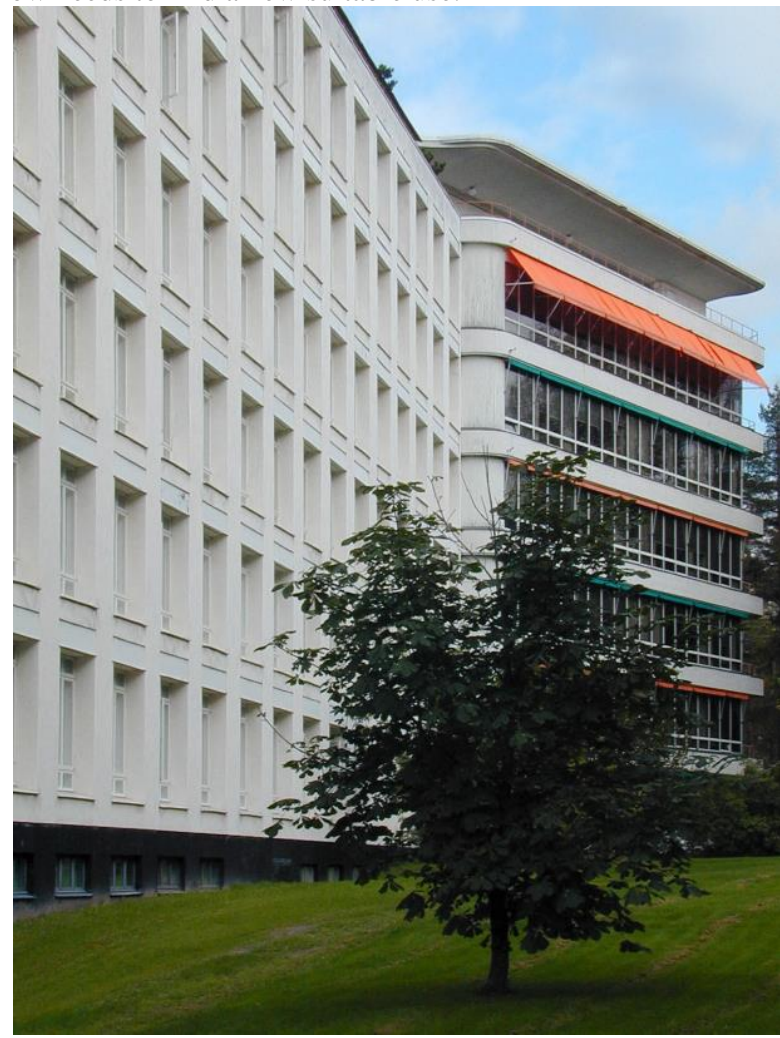

Figure 9. Paimio Sanatorium. Photography Ximo Michavila.

Educational programs are outstanding for their greater number, although in the initial call none was selected. From 2015 onwards, their presence has been constant in all the calls, except in 2016. This group includes unique works such as Faculty of Architecture and Urban Planning Center of Sao Paulo (1969) (Vilanova Artigas and Cascaldi), Ankara Faculty of Architecture (1963) (A. and B. Çinici), Bauhaus (1929) (W. Gropius), National Schools of Art of Havana (1965) (R. Porro, V. Garatti, and R. Gottardi), St. Petersburg (A. and B. Çinici), Brendan's Community School (1979) (P. and M. Doyle), Technische Universiteit Delft Auditorium (1966) (J. van den Broek and J. Bakema), School of Mathematics (1935) (G. Ponti), Engineering Building (1962) (J. Stirling and J. Gowan), Escuela Superior de Comercio Manuel Belgrano (1968) (O. Bidinost, J. Chute, J. Gassó, M. Lapacó and M. Meyer) or Gandhi Bhawan (1961) (P. Jeanneret). In this group, we could also include research centers with such emblematic pieces as Salk Laboratories (1965) (L.Khan), Einstein Tower (1921), (E. Medelsohn) and Laboratory for Faculty of Chemical Technology at Kaunas University of Technology (1935) (V. Landsbergis-Zemkalnis).

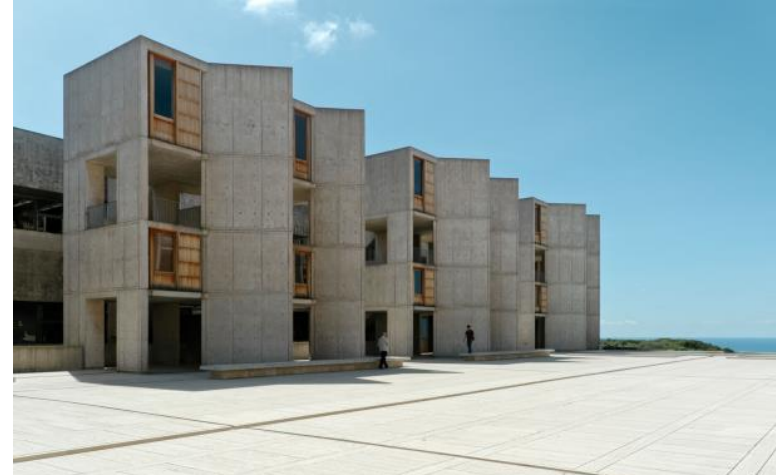

Figure 10. Salk Laboratories. Photography Ximo Michavila.

Cultural centers constitute the other large group, with fourteen works made up of museums, theatres, libraries and exhibition halls, the latter being the most numerous. Among them, it should be noted that in the first call for projects in 2014, the works are of great relevance, such as Salk Institute (1965) (L. Kahn) whose research project focuses on rehabilitating the teak woodwork and panels, Sydney Opera House (1967) (J. Utzon) and Centennial Hall (1913) (M. Berg). Cultural spaces are present in all subsequent calls and have included Arts Building and Cloister (1967) (G. Nakashima), Children's Library (1966) (Nickson and Borys), National Library of Kosovo (1971) (A. Mutnjakovic), São Paulo Art Museums Assis Chateaubriand (1968) (L. Bo Bardi), Government Museum and Art Gallery (1968) (Le Corbusier), History Museum of Bosnia Herzegovina (1963) (B. Maga', E. 'Midihen, and R. Horvat) or Uganda National Museum (1954) (E. May) and auditoriums such as the auditorium de Cheste (1969) (M. Barberá) or the Buzludzha Monument (1981) (G. Stoilov). Finally, this typology also includes exhibition halls such as the Rashid Karami International Fairground (1975) (O. Niemeyer) or Torino Esposizioni (1954) (P. L. Nervi). In this classification, we can see that there are two works that present a mixed educationalcultural program: Jewett Arts Center (1958) (P. Rudolph) with buildings for Art and Music departments and galleries for sculpture and painting collections and Arthur Neiva Pavilion (1951) (J. Ferreira) formed by classrooms and laboratories and an auditorium.

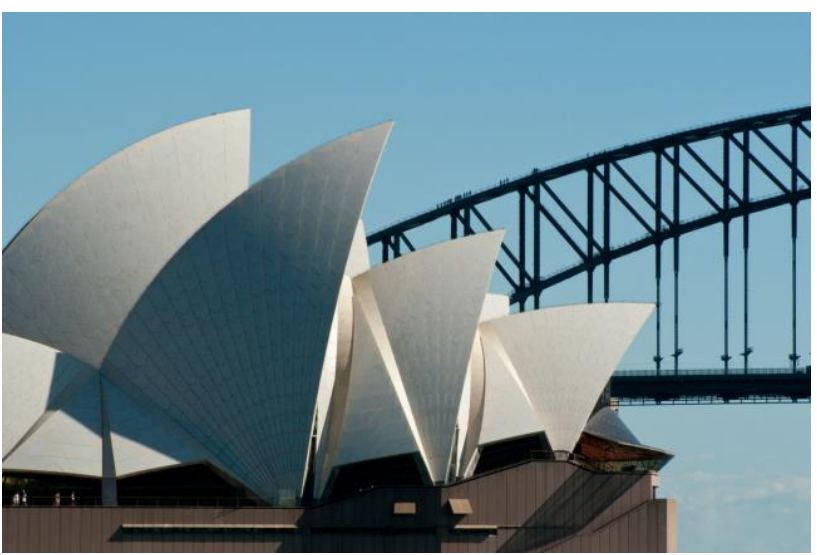

Figure 11. Sydney Opera House. Photography Ximo Michavila. 


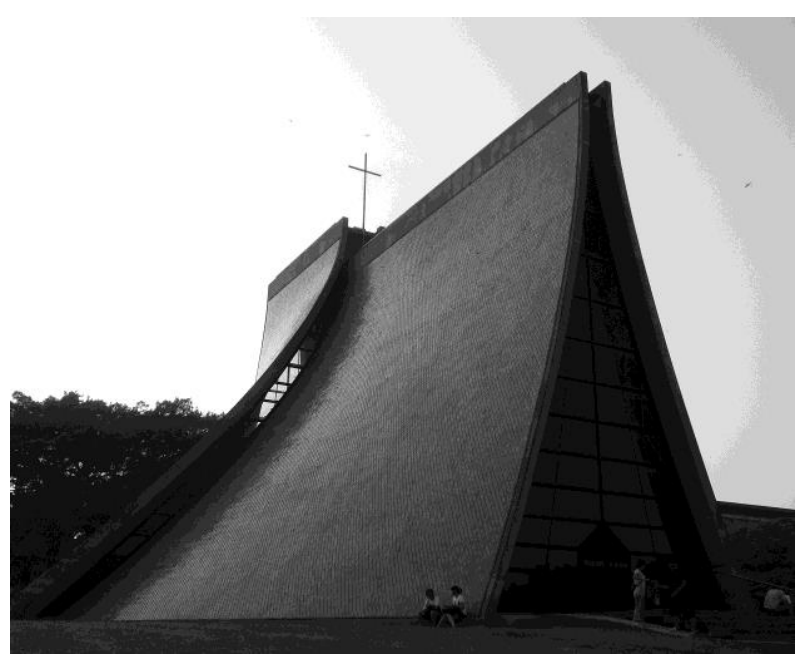

Figure 12. Henry Luce Memorial Chapel. Photography Caitriana Nicholson.

Third most representative group are service buildings where churches have a great presence. These include Henry Luce Memorial Chapel (above) (1962) by the architect Pritzker I. M. Pei, whose steeply sloping concrete roof is reminiscent of traditional Taiwanese temples, Saint John's Abbey and University Church (1961) (M. Breuer), which features a sculptural bell tower, Unity Temple (1908) (F. Ll. Wright), a pioneer in the use of concrete in public buildings, First Presbyterian Church (1958) (W. Harrison) which uses prefabricated concrete for its stained glass windows, Cristo Obrero Church (1952) (E. Dieste) an example of the characteristic plastic treatment of brick enclosures, Liverpool Metropolitan Cathedral (1967) (Sir F. Gibberd), Coventry Cathedral (1962) (Sir B. Spence) with zigzagging stone walls combined with vertical stained glass windows at the meeting points or North Christian Church (1964) (E. Saarinen) with its novel hexagonal plan. The other two works that make up the set of services are Boston City Hall Administrative Building (1968) (Kallmann, McKinnell, \& Knowles) and Beira Railway Station (1965) (F.J. de Castro, J. Garizo do Carmo, P. de Melo Sampaio).

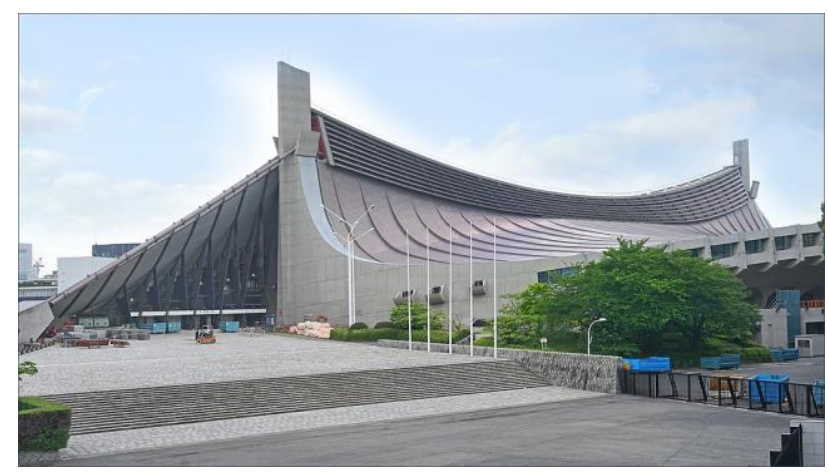

Figure 13. Yoyogi National Gymnasium. Photography JeanPierre Dalbéra.

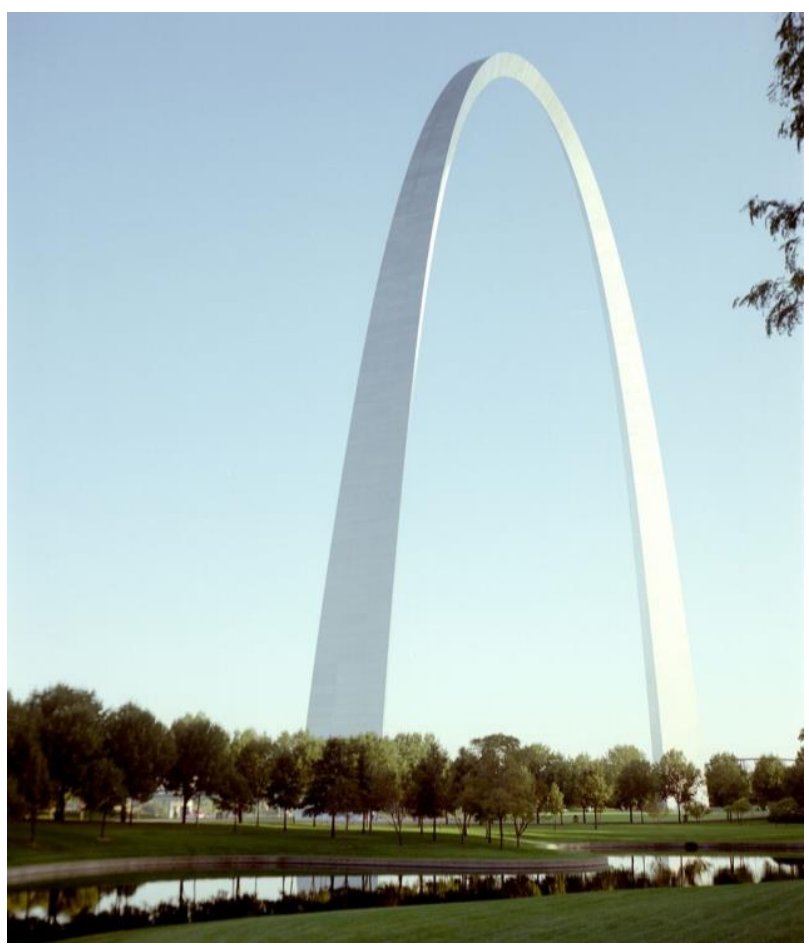

Figure 14. Gateway Arch. Photography Jefferson National Expansion Memorial, NPS.

Sports centers are represented by such emblematic buildings as Miami Marine Stadium (1962) (H. Candela) whose asymmetrical concrete umbrellas recall the image but not the geometry of the roof of Zarzuela racetrack by Eduardo Torroja, Yoyogi National Gymnasium (1964) (K. Tange) and Stadio Flaminio (1960) (P. L. Nervi).

Leisure facilities, as a means of keeping fit in the modern city, are also reflected in the Getty Foundation's KIM selection through works that present different ways of attending to this need such as Sevan Writers' Resort Guest House (1935) and the Lounge (1965) (G. Kochar and M. Mazmanyan), Sidi Harazem Thermal Bath Complex (1958) (J-F. Zevaco) and Chess Palace and Alpine Club (1973) (V. Aleksi-Meskhishvili and G. Gudushauri).

Finally, and also included in this typology is architecture as art, represented by the monumental structure of Gateway Arch (1965) (E. Saarinen) whose CMP is dedicated to the study of the stainless-steel cladding that has accumulated dirt and wear over time.

\subsection{Institution analysis}

Having made that typological classification, we will now proceed with the same methodology to analyze the institutions. We have detected twelve types of institutions that have been awarded a KIM Grant, all of them very prestigious. They are public or private entities characterized by being non-profit making.

They are mainly cultural foundations, although with very diverse interests, those that have been created for the purpose of preserving a specific work being the most numerous. This is the case of the Charles and Ray Eames House Preservation Foundation, Inc or the Sydney Opera House Trust, to name only two of the fourteen institutions. Of a similar nature, but with the specific purpose of preserving the legacy of an architect, are four foundations: Alvar Aalto Foundation, Fondation Le 
Corbusier, Frank Lloyd Wright Trust and the Lina Bo e P.M. Bardi Institute. The first three obtained the grant in the first call in 2014 while the fourth is in 2016.

Other types of cultural foundations are those of a general nature, for architectural preservation, education and the arts, such as ArchiAfrika Accra, The Writers' Union of Armenia or the Fondation Caisse de Dépôt et de Gestion, among others. A specific section among the cultural foundations is that dedicated exclusively to the preservation of heritage (monuments, ensembles and cultural landscapes) at the national level such as the German National Committee of ICOMOS and internationally such as UNESCO itself, which presented a proposal to draft a CMP for Oscar Niemeyer's Rashid Karami International Fairground in Tripoli. Even more specialized, among cultural foundations, are those that only deal with architectural heritage such as the Kosovo's Architecture Foundation or those that exclusively focus on the architectural heritage of the 20th century such as the Strutt Foundation.

To conclude the section on cultural foundations, we have established another subgroup for institutions of a religious nature. Although the works of a religious nature make up a fairly large section, however, only two of the institutions involved are exclusively religious, the Heritage Fund of Bartholomew County Inc. on behalf of Landmark Columbus and the Liverpool Roman Catholic Archdiocesan Trust.

In contrast, there are many institutions of an educational nature, including universities and research centers. This is a very large group made up of eighteen entities among which are two toplevel research centers: the Salk Institute for Biological Studies and the Leibniz-Institut für Astrophysik Potsdam which responded to the first two calls for projects in 2014 and 2015, respectively. As for the universities, their presence is more significant in the later calls of 2018 and 2019 with a total of eleven institutions. Whereas in the 2018 call all of them were European such as the Politecnico di Milano, Queen's University of Belfast, Technische Universiteit Delft, La Sapienza of Rome, the Università degli Studi di Urbino or the University of Leicester, in 2019 Latin American universities such as the Universidad Nacional de Córdoba (Argentina) also responded. It should be noted that the Universitat Politècnica de València is the only Spanish university to have received a KIM Grant Award.

Museums form another significant group. This group is made up of four entities, two of which are dedicated to architecture: the Museum of Architecture in Wrocław and the Schusev State Museum of Architecture, while the other two focus on the arts in general: the Stichting Centraal Museum and the MASP.

The last category is formed by government applicants, either at the municipal level such as the City of Boston or at the national level such as the Ministry of Tourism, Wildlife, and Antiquities of the Republic of Uganda.

\section{CONCLUSIONS}

The auditorium of the Universidad Laboral de Cheste is a point of reference for Spanish modern architecture, which is best understood in the context of the Universidad Laboral de Cheste, formed by a group of buildings with similar characteristics to those of the auditorium. Therefore, it is so important to appreciate the heritage that each part of this complex presents.
As proof of how crucial it is, the complex falls into the group of works included in the Spanish Ministry of Culture's National Plan for the Conservation of Cultural Heritage of the 20th Century, the special nature of this heritage site as well as its social fragility having been officially recognized. The plan also considers the need to establish criteria to guide conservationrestoration interventions for these works. Hence, this initiative requires the development of a coordinated action plan whose objective is research, knowledge, protection and dissemination of the various creative processes of the 20th century, as well as the definition of a working methodology that takes into account their differentiating characteristics with respect to other heritage groups. (Ministerio de Cultura y Deporte, 2013)

Finally, the auditorium presents two circumstances implicit in the ageing of modern architecture: functional obsolescence and material depletion and so it is essential to propose a Conservation and Management Plan to guide decisions and interventions for its reuse. With the aim of developing that plan, the Getty Foundation's KIM program awarded the project a grant. This project will allow us not only to achieve specific results for the auditorium but will also provide a model to be used for other buildings, both within the Universidad Laboral de Cheste complex, and in others of similar characteristics.

The important recognition of the Getty Foundation means that the auditorium of the Universidad Laboral de Cheste is situated in the international panorama of the great works of architecture of the 20th century.

\section{ACKNOWLEDGEMENTS}

We are grateful for Getty Foundation support for our CMP "Conservation Management Plan: Cheste Workers University auditorium".

\section{REFERENCES}

Andre, J., 2003. Yo estuve en Cheste. Diálogo, Valencia.

Blat, J., 2006. Fernando Moreno Barberá. Modernidad y arquitectura. Fundación Caja de Arquitectos, Valencia.

Bravo, J., 2008. Enseñanzas prácticas: espacios para la docencia y la investigación en la obra de Fernando Moreno Barberá. Universidad Politécnica de Valencia, Valencia, (Tesis Doctoral inédita leída el 06/07/2007).

Calduch, J., 2007. El envejecimiento de la arquitectura moderna. Textos dispersos en torno a la arquitectura. Generalitat Valenciana, Valencia.

Domínguez, J., Murad, M. (Ed), 2018. La Arquitectura de Fernando Moreno Barberá. Universalidad Técnica. TC Ediciones, Valencia.

Getty Foundation. Keeping It Modern https://www.getty.edu/foundation/initiatives/current/keeping_it _modern/index.html (18 April 2020)

Jordá, C., 2005. Universidad Laboral de Cheste, 1967-1968. Colegio de Arquitectos de Almería, Almeria.

Jordá, C., 2010. La Universidad Laboral de Cheste. AA.VV., Equipamientos I. Lugares Públicos y nuevos programas. Registro docomomo Ibérico 1925- 1965, Fundación Caja de Arquitectos, Barcelona. 
Jordá, C., Palomares, M., 2013. The Universidad Laboral de Cheste, a Modern Heritage Site Under Threat. Docomomo Journal 49, 78-81.

Ministerio de Cultura y Deporte, 2013. Plan Nacional de Conservación del Patrimonio Cultural del Siglo XX. Available at http://www.culturaydeporte.gob.es/planes-nacionales/planesnacionales/conservacion-patrimonio-cultural-sigloxx.html $\quad(18$ April 2020)

Moreno Barberá, F., 1970. Centro de Orientación de Universidades Laborales Jesús Romeo, Cheste, Valencia. Revista Arquitectura 142, 17-25.

Moreno-Barberá von Hartenstein, F., 2014. Fernando Moreno Barberá: Un arquitecto en Turismo. General de Ediciones de Arquitectura, Valencia.

Palomares, M., 2012. La singularidad de la Universidad Laboral de Cheste: la gran escala, el abandono y la necesidad de intervenir. VIII Congreso Docomomo Ibérico. Secretaría General Técnica Subdirección General de Documentación y Publicaciones, JUNTA DE ANDALUCÍA Consejería de Cultura, Fundación DOCOMOMO Ibérico, Málaga.

Zafrilla, R., 1998. Universidades laborales. Un proyecto educativo falangista para el mundo obrero, 1955-1978. Universidad de Castilla La Mancha, España. 